\title{
Development Of Larvae Rainbow Fish Boesemani (Melanotaenia boesemani): Phase Depreciation of Yellow Egg, Forming Eyes and Opening of Mouth
}

\author{
Dewi Elfidasari ${ }^{1}$, Frenzysca Yuliani ${ }^{1}$, Tutik Kadarini ${ }^{2}$, Siti Zuhriyyah Musthofa ${ }^{2}$ \\ ${ }^{1}$ Program Study of Biology, Faculty of Science and Technology \\ University of Al Azhar Indonesia \\ ${ }^{2}$ The Center of Research and Development of Ornamental Fish Culture \\ Email contact: d_elfidasari@uai.ac.id
}

\begin{abstract}
One of the factors that caused larval mortality is the availability of food which is not in accordance with the mouth opening. At the same time the larvae require considerable energy to the development of organs. The Completeness of organs used in feed searching as the eyes is also becoming important. The larvae use eyes to see the feed material in their surrounding waters. This study aimed to measure the volume of egg yolk, eye diameter and wide mouth opening during larval development rainbow fish boesemani (Melanotaenia boesemani). The stages of the research include larval maintenance, depreciation egg yolk observations, calculate the size of the increase in larval eye and mouth openings. The results of this study showed that newly hatched rainbow boesemani larvae have egg yolks, eyes and mouth. The newly hatched larvae have a yolk volume average of $0.053 \mathrm{~mm}^{3}$. Egg yolks will expire at the time of 2 days old larvae. The formation of the eye, has occurred inside the eggs and newly hatched larvae have an average diameter of eye of $0.459 \mathrm{~mm}$. The newly hatched larvae have a wide mouth opening average of $0.229 \mathrm{~mm}$. An larvae older than 21 days and 30 days has a wide mouth opening average of $0.82 \mathrm{~mm}$ and $1.725 \mathrm{~mm}$.
\end{abstract}

Keywords - Rainbow fish Melanotaenia boesemani, larval development, egg yolks, eyes, mouth

\section{INTRODUCTION}

Indonesia has many kinds of ornamental fish with high economic value. One of ornamental fish in Indonesia is boesemani rainbow fish. Boesemani rainbow fish price reaches $\pm \$ 8.90$ [1]. In systematically, rainbow fish boesemani included in Actinopterygii class, Atheriniformes order, Melanotaeniidae family, Melanotaenia genus, and Melanotaenia boesemani species [2]

Rainbow fish breeding is done to meet the demand for fish lovers, so the rainbow fish maintained its continuity in nature. Rainbow fish breeding process has several problems, one of which is a fairly high larval mortality [3] [4] [5]. The main factor causing the death of the larvae is the availability of food that does not comply with the mouth opening. At the same time the larvae require considerable energy. Food that is larger than the larval mouth opening causes the larvae are not able to consume the food. Therefore there is a critical period in the rainbow fish larvae.

There is still limited information regarding the critical period of rainbow fish boesemani causes research is needed to explain the stages of the development and formation of organs related to feed intake process. It is necessary to reduce the mortality of larvae [4]. One way is to observe the larvae to obtain information on the larval development is the time covering the yolk out, mouth opening, and eyes can help breeders to cope with the death of the larvae. Breeders can determine the time of feeding and the type of feed that is suitable for the larvae.

This study aims to describe the process of yolk shrinkage, formation of the eyes and mouth openings of boesemani rainbow fish (Melanotaenia boesemani). The results of this study are expected to be a source of information for the community, especially the ornamental fish breeders to reduce 
the mortality of fish larvae and increase the production of rainbow Boesemani in the cultivation process.

\section{RESEARCH METHODS}

The object of research is boesemani rainbow fish embryos and larvae. The study was conducted at the Center of Research and Development of Ornamental Fish Culture in Perikanan Road No 13 RT 01 RW 02 Sub-District Pancoran Mas, Depok, West Java. Time of research is between July and October 2013.

The tools used in the study include a plastic container with a diameter of $8.5 \mathrm{~cm}$ height $20 \mathrm{~cm}$ as a larval rearing, DO meter to measure temperature and dissolved oxygen content. $\mathrm{pH}$ meter to measure the $\mathrm{pH}$ of the water. Olympus BX41 microscope with a magnification binocular 10X4 equipped with a Panasonic digital camera WF-CP24EX to observe embryonic development. The images of the microscope will be analyzed using the software "ImageJ ®".

Larval stage of the research include breeding, depreciation yolk observation, measuring the increase in the size of the larvae eyes and mouth openings. The eggs hatch into larvae which had been transferred to the larval rearing a plastic container with a diameter of $8.5 \mathrm{~cm}$ height $20 \mathrm{~cm} .1$ day old larvae swam well and had to be fed rotifera 3 times a day "ad-libitum". Larvae maintained at a temperature of $27-28^{\circ} \mathrm{C}$ and 2-3 ppm DO.

The Solubility of oxygen in the place maintenance of larvae is 2-3 ppm, because we don't put aeration in there. We avoid any challenge for development of larvae, because the larvae very small and their organ still develop and grow, so they cannot swim well. We hope continued research about aeration, so we can know the best measure of aeration for development of larvae

The newly hatched larvae were observed the shrinkage of the yolk, the development of the eye and mouth openings using a microscope. Observations made \pm 1 month every 3 times a week until the larvae turn into a seed. Larvae anesthetized with phenoxy ethanol $100 \% \quad 0.1 \mathrm{ml}$ were mixed with $10 \mathrm{ml}$ of distilled water prior to observation. The data recorded includes the volume of egg yolk, eye diameter, and the width of the mouth opening.
Measurement of the diameter of the egg yolks until the yolks do rainbow fish runs out. Yolk volume calculated using the following formula [3]:

Yolk volume $\left(\mathrm{mm}^{3}\right)=\Pi / 6 \mathrm{C}_{1} \mathrm{C}_{2}{ }^{2}$

$\mathrm{C}_{1}=$ Longest axis either side of the egg yolk

$\mathrm{C}_{2}=$ Shortest axis either side of the egg yolk

Wide mouth opening is calculated using the formula [3]:

The width of the mouth opening $(\mathrm{mm})=$

Jaw Length $X \sqrt{ } 2$

\section{RESULTS AND DISCUSSION}

This study provides information that fish larvae newly hatched rainbow boesemani still have yolk as food reserves (Figure 1). The volume of egg yolk in the newly hatched larvae average of $0.053 \mathrm{~mm}^{3}$ and shrinking during its development. The most of depreciation yolk volume happened when the larvae is 1 day old. 2 day old larvae were mostly already run out of the egg yolk (Figure 2).

Egg yolk is a larval food reserves which will run out around 2-3 days so it is necessary to be replaced by the natural food [6]. Newly hatched kurumoi rainbow fish larvae yolk volume average of 0.195 $\mathrm{mm}^{3}$. Yolk absorption is affected by the age, as it related to the growth and development of the larvae. On the second day after hatching egg yolk volume is completely run out [4]. Red rainbow fish larvae newly hatched have an average eggs volume of $0.171 \mathrm{~mm}^{3}$ and depleted when larvae aged 108 hours [6].

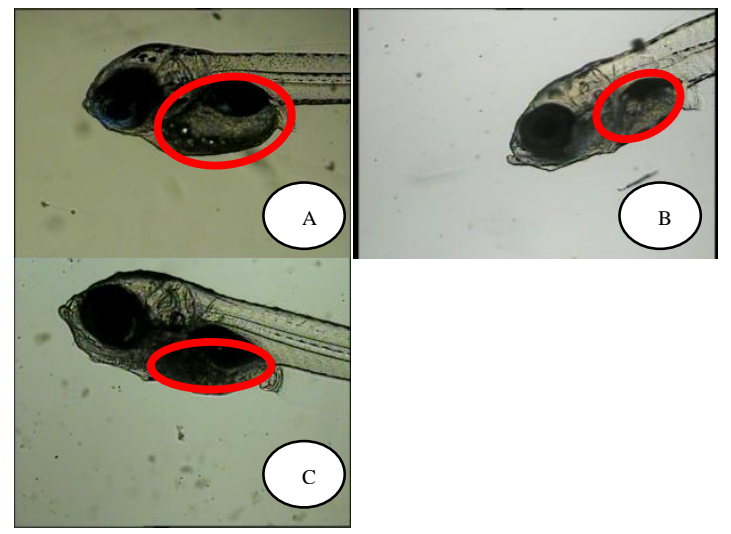

Figure 1. Boesemani rainbow fish larvae (A) Egg yolks age 0 days, (B) Egg yolks 1 day of age, (C) Egg yolks 2 days of age

A Larvae that did not have egg yolk anymore began searching for source of the feeding material itself. 
Availabillity of food resources in waters where larvae live must be adjusted to the developmental stages of the rainbow fish. It required precision on both timing and type of fish food adjusted with the volume of egg yolk and larval mouth opening width.

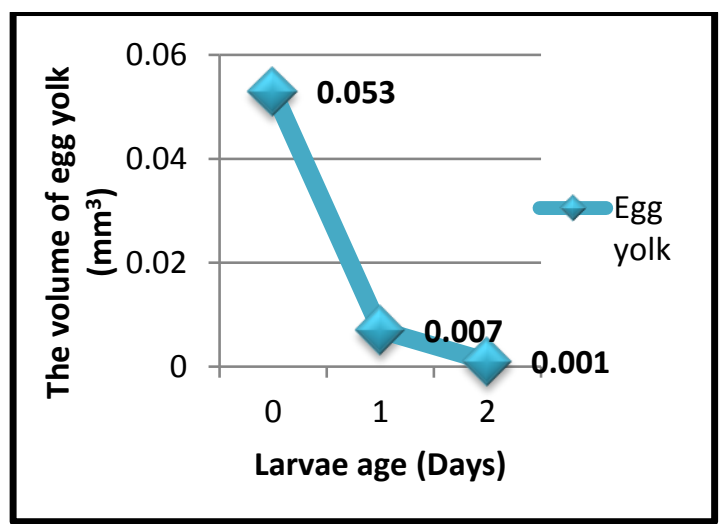

Figure 2. The volume of egg yolk rainbow fish larvae boesemani

The observation of formation phase of rainbow boesemani eyelets, showed that a newly hatched larvae with average total length of $4.71 \mathrm{~mm}$ and $4.21 \mathrm{~mm}$ standard length, own eyes and mouth. The eye is one of the vital organs in the feed search process [4]. Fish using a fish eye to see the waters surrounding environment and detect the presence of food.

Kurumoi rainbow fish larvae that hatch are known to have had pigmentation (Figure 3). Pigmentation on the eye will cause a black color on the organ. When the red rainbow fish hatch already has solid black eyes [6]. Boesemani rainbow eyelets formed in the egg phase of organogenesis. Red rainbow fish have eye spots 16 hours 52 minutes from the initial phase of organogenesis [3].

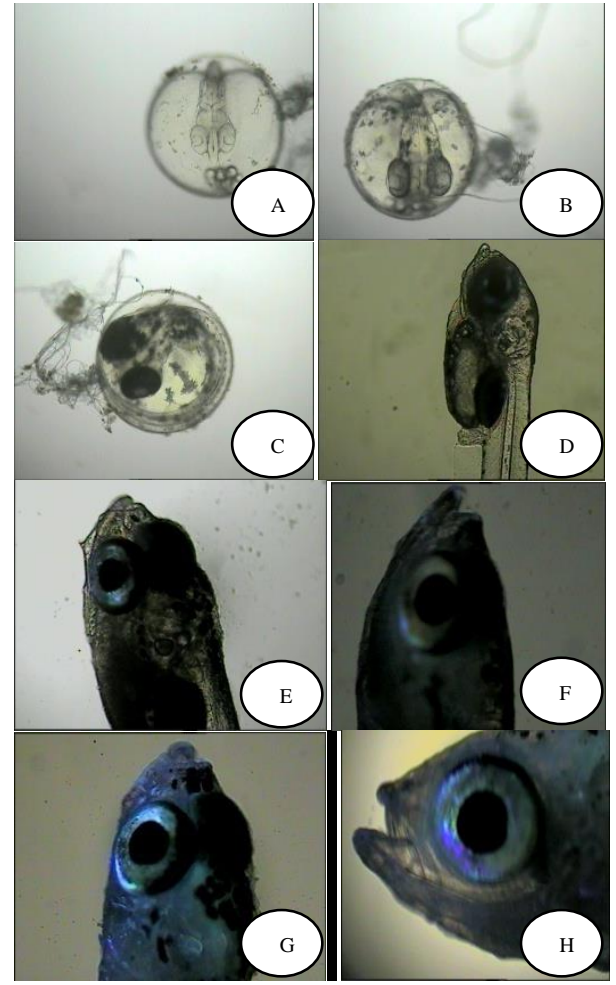

Figure 3. Boesemani rainbow fish eye (A) 26 hours 11 minutes, (B) 49 hours 11 minutes, (C) 72 h, (D) Newly hatches, (E) 1 week, (F) 2 weeks, (G) 3 weeks, (H) 30 days

Observations on rainbow fish boesemani eggs begin after 2 cells is seen. Boesemani rainbow fish eye seen at the egg after 26 hours 11 minutes (Figure 3A). Eye spots clearly visible after 49 hours 11 minutes (Figure 3B). Eyes seen blackened after 72 hours (Figure 3C). When the larvae hatch it has eyes with diameter of $0.459 \mathrm{~mm}$ (Figure 3D). Larvae eye diameter increase with larvae age. 1 week old larvae had an average eyes diameter of $0.649 \mathrm{~mm}$ (Figure 3E). Diameter of 2 week old larvae average of $0.818 \mathrm{~mm}$ (Figure 3F). 3 week old larvae not showed considerable development of the eye diameter. Diameter of 3 week old larvae on average of only $0.914 \mathrm{~mm}$ (Figure 3G). 
The largest increase in developments of eyes diameter occurring after the larvae is older than 3 weeks age (Figure 4). A larvae aged 30 days or has been turned into the seeds have average diameter of $1.253 \mathrm{~mm}$ eye with a total length of $13.8 \mathrm{~mm}$ (Figure 3H). The Developments of eyes diameter is related to the total body length of larvae [7].

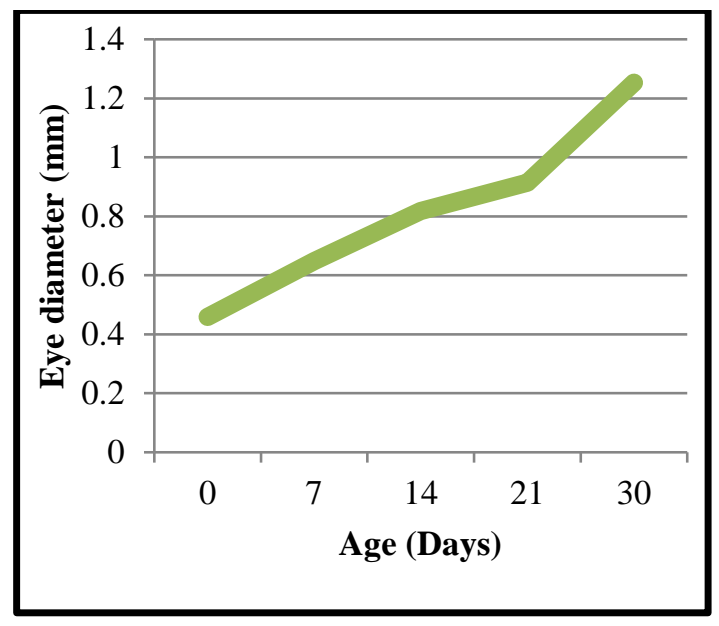

Figure 4. The development of rainbow fish eye diameter boesemani

The observation of the formation phase of mouth opening on boesemani rainbow fish larvae showed that a newly hatched larvae have a wide mouth opening average of $0.229 \mathrm{~mm}$. Wide mouth opening has grown hand in hand with larvae age (Figure 5). After the larvae older than 21 days the size of the mouth opening width is increased with considerable amount of $0.82 \mathrm{~mm}$. An 30 day old larvae have a mouth opening width average of $1.725 \mathrm{~mm}$.

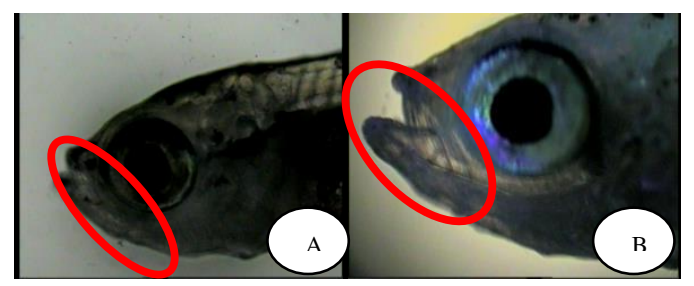

Figure 5. Boesemani rainbow fish larvae (A) Mouth age of 14 days, (B) 30 days of age mouth

Rainbow fish larvae mouth widening will ease the process of feed intake of the same size food with the size of the mouth opening. 0-7 day old larvae with a width of $0.229-0.451 \mathrm{~mm}$ mouth opening can be fed infusoria or rotifera. Larvae 7-21 days old with 0.451-0.905 mm mouth opening can be provided rotifera or Artemia sp. in the form of naupli. Moina sp. can only can be fed when the larvae 21-30 days old with 0.905-1.725 mm width of the mouth opening (Figure 6).

Rainbow fish larvae have mouth with 2 jaw which is maxilla (upper jaw) and mandible (lower jaw). Upper jaw move after Lower jaw move which eventually moving together [4] [6]. A newly hatched kurumoi rainbow fish larvae has imitial mouth opening with size of $0.081 \mathrm{~mm}$, while the red rainbow fish larvae mouth opening are $35 \mu \mathrm{m}$ [6]. Kurumoi rainbow fish larvae aged 1-4 days has mouth opening of 0.081-0.094 mm, age 5-16 days of 0.100-0.206 mm, and the age of 17-21 days of $0.247-0.411 \mathrm{~mm}$ [4]

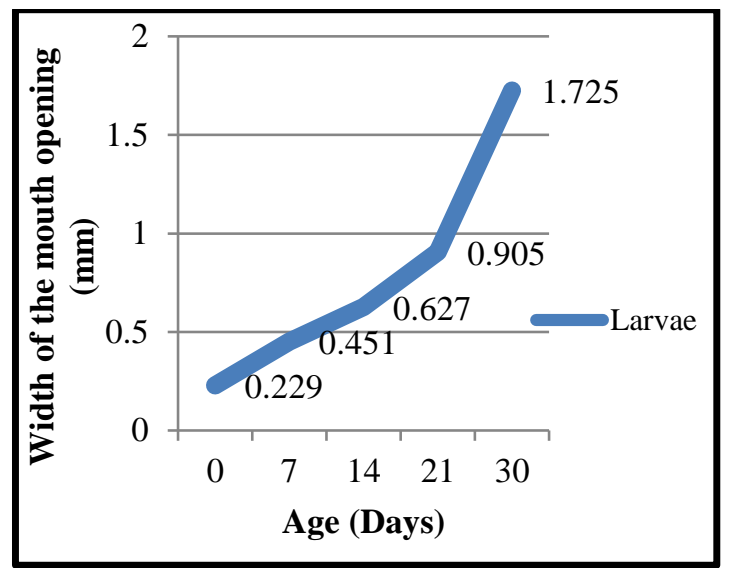

Figure 6. Rainbow fish boesemani larvae mouth opening width

Natural feeding process must be adjusted to the volume of egg yolk, the size of the mouth opening, and completeness of the larval digestive organs such as the intestines and the anus. It is intended that the food can be directly consumed by fish larvae. Boesemani rainbow fish larvae 0-21 days old can be fed rotifera, while the 21-30 day old larvae can be given Moina sp.. Kurumoi rainbow fish larvae 3-10 days old can be given infusoria. 1130 days old kurumoi rainbow fish larvae may be given Moina sp. as natural food [8].

Betta fish are 0-15 days old can be given rotifera and naupli of Artemia sp. [7]. Moina sp. has a spherical shape with a diameter of 0.9-1.8 $\mathrm{mm}$ and reddish [9]. This fits the mouth opening when the larvae older than 21 days. Rotifera have a size of $0.092 \mathrm{~mm}$ in males and females measuring $0.17 \mathrm{~mm}$ 
so the 4 days old larvae can eat the rotifera especially male rotifera. Artemia sp. the rate of 0.4 mm sized naupli [3].

\section{CONCLUSION}

From these results it can be concluded that newly hatched rainbow boesemani fish larvae has a total length of an average of $4.71 \mathrm{~mm}$, still has the egg yolks with a volume of $0.053 \mathrm{~mm}^{3}$, the yolk will run out on a 2 day old larvae. The newly hatched larvae also have an eye with a diameter of 0.459 $\mathrm{mm}$ and a mouth with an mouth opening average of $0.229 \mathrm{~mm}$ wide. Eyes and mouth organ formation has occurred in the egg (embryogenesis period). The diameter of the eye and mouth openings will increase along with the growth and development of the larvae.

\section{ACKNOWLEDGEMENT}

This study received funding from LP2M UAI 2013 and facilities of The Center of Research and Development of Ornamental Fish Culture Depok, for that thank you so much to the leadership, staff researchers and all laboratory personnel who have guided and helped this research.

\section{REFERENCE}

[1] Anonymous, "http://www.aquariumfish.net/catalog_page s/cyprinids/rainbowfishes.htm," 2013. [Online]. [Accessed 23 June 2013].

[2] A. GR, "A genetics classification of the rainbowfishes (Family Melanotaedae): Record or The Western Australian Museum," Australian Museum, Australia, 1980.
[3] F. Nugraha, "Embriogenesis dan perkembangan larva ikan rainbow (Glossilepis incises)," [Skripsi] Institut Pertanian Bogor, Bogor, 2004.

[4] T. Kadarini, M. Zamroni and E. Pambayuningrum, "Perkembangan larva ikan rainbow kurumoi (Melanotaenia parva)," J. Riset Akuakultur, vol. 8, no. (1), pp. 77-86, 2013.

[5] C. Humphrey, D. Klumpp and R. Pearson, "Early development and growth of the eastern rainbowfish, Melanotaenia spendida spendida (Peters), Morphogenesis and ontogeny," J. CSIRO Marine and Freshwater Research, vol. 54, pp. 17-25, 2003.

[6] S. Murniasih, T. Kadarini and M. Zamroni, "Laju penyerapan kuning telur dan bukaan mulut awal larva ikan rainbow merah (Glossolepis incius)," in Forum inovasi teknologi akuakultur, 19-21 Juli 20122, Bali, 2011.

[7] R. Rahmawati and E. Kusrini, "Ontogeni dan survival activity index larva ikan cupang alam (Betta imbellis Ladiges 1975) hasil transgenik.," in Forum inovasi teknologi akuakultur, Lombok, 2013.

[8] T. Kadarini, A. Mertayasa and E. Kusrini, "Dukungan pembenihan ikan rainbow boesemani (Melanotaenia boesemani) terhadap sumber daya ikan di Depok," in Forum Nasional Pemacuan Sumber Daya Ikan III, Bandung, 2011.

[9] Chumadi, S. Ilyas, M. Yunus, M. Sahlan, R. Utami, A. Priyadi, P. Imanto, S. Hartati, M. Bastiawan, Z. Jangkaru and R. Arifudin, "Petunjuk teknis: Budidaya pakan alami ikan dan udang," Pusat Penelitian dan Pengembangan Perikanan, Badan Penelitian dan Pengembangan Pertanian, Jakarta, 1990. 